\title{
Rare huge cold abscess and paraplegia in a young man with multidrug-resistant spinal tuberculosis
}

\author{
Jinpeng Du, Wentao Wang \\ Department of Spine Surgery, Honghui Hospital, Xi'an Jiaotong University, Xi'an, China \\ Correspondence to: Wentao Wang. Department of Spine Surgery, Honghui Hospital, Xi'an Jiaotong University, Friendship East Road, Xi'an, China. \\ Email: spine13087540521@126.com.
}

Submitted Apr 16, 2020. Accepted for publication Jun 28, 2020.

doi: 10.21037/qims-20-575

View this article at: http://dx.doi.org/10.21037/qims-20-575

\section{Introduction}

According to the 2016 WHO Global tuberculosis (TB) report (1), there were about 10.4 million new TB cases worldwide in 2015; of these, 480,000 were multidrug resistant TB (MDR-TB) patients, accounting for about $20 \%$ of global TB cases. Bone and joint TB, especially spinal $\mathrm{TB}$, is a common extrapulmonary secondary TB. Drug resistance negatively affects the prognosis of patients with spinal TB and greatly increases the risk of surgery (2).

A 27-year-old young man was admitted to our hospital with weakness and numbness in both legs. The patient reported a history of neck pain, night fevers, night sweats and weight loss for 4 months. He had smoking history for 10 years, and was used to staying up all night in the Internet cafe, with potential exposure due to an endemic zone for TB. Cervical spine TB was diagnosed at a local hospital according to assessment based on clinical symptoms, imaging findings and blood test results, and a standardized 4-drugs (Isoniazid, rifampicin, pyrazinamide, ethambutol) antituberculosis treatment plan was given [3HRSE(Z)/6-15HRE(Z)]. However, he did not take his medicines regularly. Symptoms of hypoesthesia in both legs, walking weakness, dysphagia, urinary frequency and urgency appeared 2 months earlier and gradually worsened.

On examination, his legs showed weakness and numbness, hypoesthesia of skin below the level of nipple. His key muscle strength was $0-\mathrm{II}$, the deep reflection weakened, and Babinski sign was positive. The patient was HIV-negative, T-Spot for TB infection was positive. Results of sputum smear and sputum culture of Mycobacterium
TB were negative. X-ray showed no obvious abnormality in the lungs, while lung CT showed that a flaky high-density shadow in the size of $1.6 \times 1.0 \mathrm{~cm}$ at the tip of the right lung, with multiple nodules around it, suggesting chronic TB changes. Spine MRI showed significant compression to cervical spinal cord, bone destruction of the $\mathrm{C} 6 / \mathrm{C} 7$ compatible with mass tuberculous cold abscesses beside the vertebra (Figure 1A,B), and a huge loculated tuberculous cold abscess beside lumbar spine (Figure 1C). Spinal CT showed multiple bone destruction in cervical vertebrae and thoracic vertebrae. The bone destruction of $\mathrm{C} 7$ vertebrae was the most serious, and half of the vertebrae and most of the appendages on the right side were completely destroyed, and multiple punctate dead bones were formed. The intervertebral space of C6/7 narrowed, C6 vertebral body was partially destroyed (Figure 1D,E).

Using fine needle aspiration, a sample from the man's lumbar abscess was obtained. Examination shows the tubercle bacilli was resistant to both rifampicin and isoniazid after the liquid culture and drug sensitive test. In order to rescue the damaged spinal cord, antituberculosis plan was adjusted (Levofloxacin, streptomycin, telizone, ethambutol) and nutritional support was given according to national guidelines for 4 weeks. After inflammatory indexes were significantly reduced, the patient received one-stage debridement, radical decompression and internal fixation by cervical anterior and posterior approach (Figure $1 F)$. After 6 months of inpatient antituberculosis treatment (Intensive stage of 2 months: levofloxacin $750 \mathrm{mg} / \mathrm{d}$, streptomycin $750 \mathrm{mg} / \mathrm{d}$, prothionamide $1,000 \mathrm{mg} / \mathrm{d}$, ethambutol $1,000 \mathrm{mg} / \mathrm{d}$. Consolidate period of 4 months: levofloxacin 

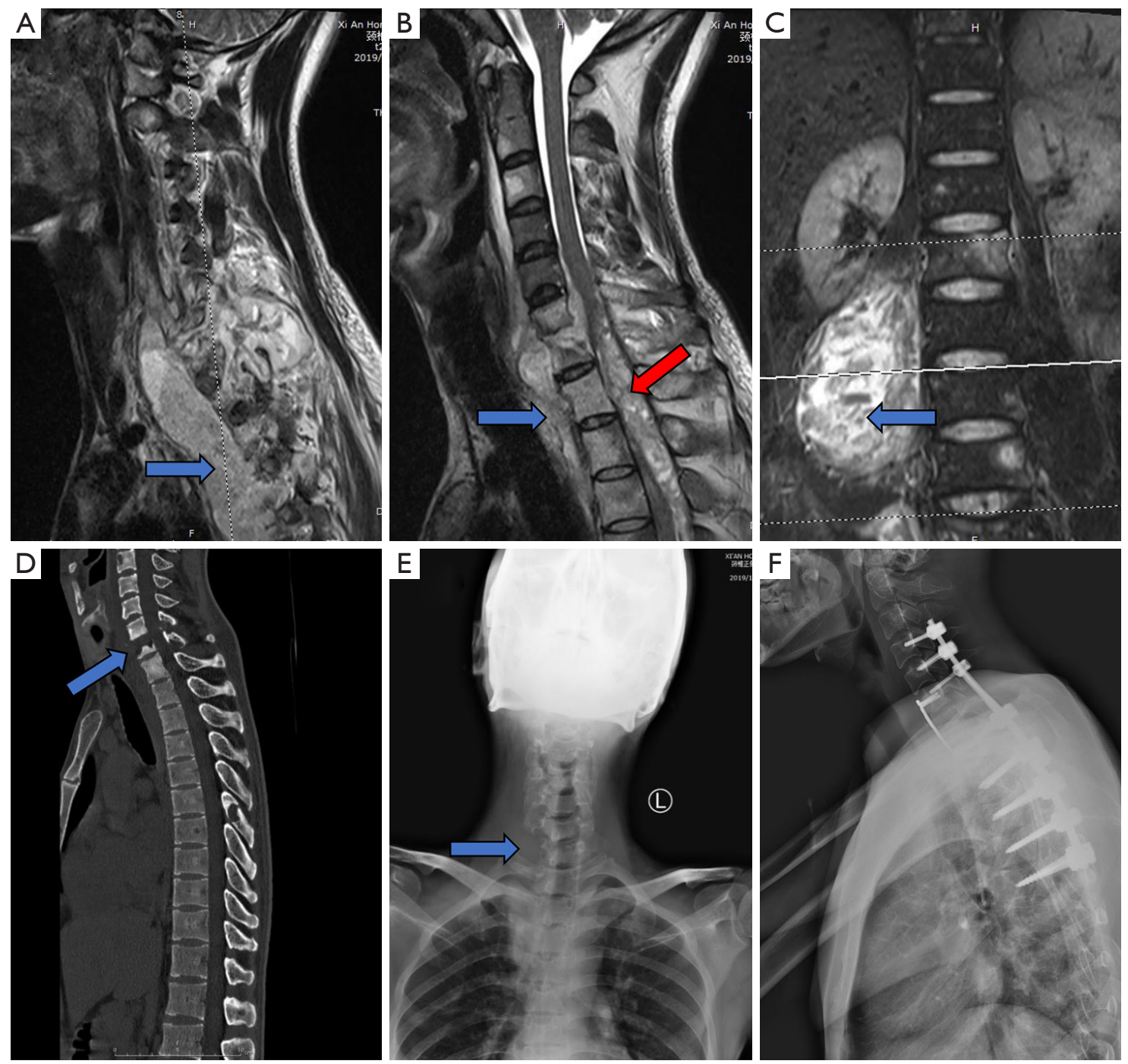

Figure 1 Spine TB with a huge cold abscess. Cervical spine MRI shows that a posterior pharyngeal wall abscess (blue arrow) erodes the vertebrae and disc and surrounded the posterior edge of the vertebral body (A); mycobacterium TB infected adipose tissue proliferated in the spinal canal to form a jelly-like gray cold abscess (red and blue arrow) and presses the spinal cord (B); lumbar spine MRI shows a huge abscess (blue arrow) wrapped psoas muscle (C); CT scan and X-ray of spine shows multiple osteolytic lesions of the cervical (blue arrow), thoracic and lumbar vertebrae, most severe at the $\mathrm{C} 7$ vertebra $(\mathrm{D}, \mathrm{E})$; postoperative $\mathrm{X}$-ray $(\mathrm{F})$. TB, tuberculosis.

$300 \mathrm{mg} / \mathrm{d}$, streptomycin $750 \mathrm{mg} / \mathrm{d}$, ethambutol $750 \mathrm{mg} / \mathrm{d}$ ) and professional rehabilitation training, the patient recovered the ability to walk, and his paraspinal cold abscess at the lumbar was significantly reduced. More debridement was not required.

Infectious TB remains a serious challenge for developing countries. Young people whose resistance declined due to irregularities in their daily routine and diet are at a high risk of contracting mycobacterium TB (3). Once the drug is not taken regularly according to the protocol after infection and has progressed to multidrug-resistant spinal $\mathrm{TB}$, treatment become more difficult. Our case reinforces the importance of patient's compliance to antituberculosis treatment for early spinal TB.

\section{Acknowledgments}

Funding: None. 


\section{Footnote}

Conflicts of Interest: Both authors have completed the ICMJE uniform disclosure form (available at http://dx.doi. org/10.21037/qims-20-575). The authors have no conflicts of interest to declare.

Ethical Statement: Written informed consent was obtained from the patient for publication of this study and any accompanying images.

Open Access Statement: This is an Open Access article distributed in accordance with the Creative Commons Attribution-NonCommercial-NoDerivs 4.0 International License (CC BY-NC-ND 4.0), which permits the noncommercial replication and distribution of the article with the strict proviso that no changes or edits are made and the original work is properly cited (including links to both the formal publication through the relevant DOI and the license). See: https://creativecommons.org/licenses/by-nc-nd/4.0/.

\section{References}

1. World Health Organization. Global tuberculosis report 2016. Geneva: World Health Organization, 2016.

2. Daley CL, Caminero JA. Management of multidrugresistant tuberculosis. Semin Respir Crit Care Med 2018;39:310-24.

3. Hasan GA, Kani SM, Alqatub A. Tuberculous lumbar spinal epidural abscess in a young adult (case report). SICOT J 2018;4:5.
Cite this article as: Du J, Wang W. Rare huge cold abscess and paraplegia in a young man with multidrug-resistant spinal tuberculosis. Quant Imaging Med Surg 2020;10(10):2078-2080. doi: 10.21037/qims-20-575 